\title{
Comprehensive Evaluation of Salt Tolerance in Asparagus Germplasm Accessions (Asparagus officinalis L.) at Different Growth Stages
}

\author{
Huimin Gao, ${ }^{1}$ Xuhong Zhang, ${ }^{1,2}$ Yuqin Liang, ${ }^{1}$ Lingdi Dong, ${ }^{1}$ Changzhi Han, ${ }^{3}$ \\ and Yanpo Cao $\mathbb{D i}^{1}$ \\ ${ }^{1}$ Institute of Cash Crops, Hebei Academy of Agriculture and Forestry Sciences, Shijiazhuang, Hebei 050051, China \\ ${ }^{2}$ Shijiazhuang Department of Landscaping Management, Shijiazhuang 050061, China \\ ${ }^{3}$ College of Biodiversity Conservation and Utilization, Southwest Forestry University, Kunming 650224, China
}

Correspondence should be addressed to Yanpo Cao; caoyanpo@126.com

Received 17 December 2020; Revised 18 February 2021; Accepted 2 March 2021; Published 15 March 2021

Academic Editor: wujun Ma

Copyright (C) 2021 Huimin Gao et al. This is an open access article distributed under the Creative Commons Attribution License, which permits unrestricted use, distribution, and reproduction in any medium, provided the original work is properly cited.

\begin{abstract}
The screening and cultivation of salt-tolerant crops are becoming more and more important owing to the constant increase in the saline soil area worldwide. Asparagus (A. officinalis L.) is a highly nutritious vegetable crop and widely consumed globally for a long time; however, little research has been done on asparagus. In this study, the salt tolerance of 95 asparagus germplasm accessions was evaluated at three growth stages (germination, seedling, and adult stages) under both salt-stressed and control conditions. Results showed that the growth parameters of most germplasm accessions were obviously inhibited by salt stress. The mean value of the seed germination rate at the germination stage decreased by half under salt-stressed conditions, the mean saltinjury index at the seedling stage reached 57.68\%, and the fresh weight of the aboveground part (FWA) and the dry weight of the aboveground part (DWA) decreased the most among the traits determined at the adult stage by more than $60 \%$. Our study screened out 30,19, and 18 tolerant germplasm accessions (including highly salt-tolerant and salt-tolerant germplasm accessions) at the germination stage, seedling stage, and adult stage, respectively. Among them, two germplasm accessions (Ji08-2 and Jx1502) were simultaneously identified to be tolerant in all three growth stages, while other germplasm accessions were tolerant only at one or two stages. Thus, the salt tolerance of asparagus has periodic characteristics and changes throughout the lifecycle, and the identification of salt tolerance at all the main growth stages facilitates adequate assessment and application of tolerant germplasm accessions.
\end{abstract}

\section{Introduction}

Vegetables are necessary food in people's daily life. With the improvement of living standard, people have more and more demand on the quantity and nutrition of vegetables. However, vegetables often suffer great damage from salt stress during their growth thus leading to the decrease of yield and quality [1]. Therefore, screening and cultivating salt-tolerant germplasm is set to become an alternative way to make full use of large areas of saline soil and to stabilize vegetable yield. Asparagus (Asparagus officinalis L.) is considered high in nutrients, including vitamins, steroidal saponins, flavonoids, minerals, and amino acids [2]. It has been widely consumed globally for a long time, making it an economically valuable plant. China is the largest asparagus producer and exporter in the world, which accounts for over $40 \%$ of the global planting area and yield of asparagus. Asparagus has strong salt tolerance and can grow normally in moderate saline-alkali soil below $0.3 \%$ [3]. In this environment, the impediment of upward transport of $\mathrm{Na}^{+}$by asparagus roots and the redistribution of $\mathrm{Na}^{+}, \mathrm{K}^{+}$, and $\mathrm{Ca}^{2+}$ on the organ level play key roles in asparagus adaptation to salt stress [3]. In addition, the enhanced ROS-scavenging capacity and carbon metabolism were also demonstrated as 
important salt tolerance mechanisms in asparagus plants [4]. However, there are great differences in salt tolerance among varieties in severe saline-alkali soil, where only some varieties can grow normally $[3,5]$. Therefore, it is important to identify and screen salt-tolerant asparagus germplasm accessions for research on the salt resistance mechanisms, breeding, and cultivation of salt-tolerant varieties in salinealkali soil.

In recent years, considerable research on the identification of salt-tolerant germplasm has been carried out in multiple vegetables around the world, such as cucumber, tomato, and chilli [6-8], from which some success and experience have been achieved. However, in asparagus, the research is still in the initial stage and lacks depth and breadth. From many previous studies, we know that plant salt tolerance was evaluated at the germination stage and seedling stage due to their prerequisite roles in determining yield [6-8] while the results were usually different in the entire growth period, including the adult stage, another critical stage closer to actual production. Thus, salt-tolerant identification at the adult stage must be conducted before plants are applied in actual production in saline-alkali soil, which will be more reliable combined with identification at the germination stage and seedling stage.

The aims of this study were to screen the different germplasm accessions of asparagus for salt tolerance and to determine more reliable screening stages. In the present study, 95 asparagus germplasm accessions were evaluated and screened at the germination stage, seedling stage, and adult stage for salt tolerance, which further builds a foundation for research on asparagus salt resistance mechanisms and the breeding of salt-tolerant varieties.

\section{Materials and Methods}

2.1. Plant Materials. A total of 95 germplasm accessions of asparagus (Asparagus officinalis L.) were collected from various countries, including 31 from the United States, 11 from Holland, 6 from New Zealand, 5 from Italy, 3 from Germany, 3 from Japan, 1 from the United Kingdom, and 35 from China (Table 1). Seeds of these germplasm accessions were provided by the Institute of Cash Crops, Hebei Academy of Agriculture and Forestry Sciences.

\subsection{Identification of Salt Tolerance at the Germination Stage.} Seeds were first disinfected in ozone for 30 minutes. Next, 50 plump seeds of similar size were selected from each germplasm for germinating in Petri dishes $(10 \mathrm{~cm}$ diameter $)$ with three layers of filter paper soaked in $10 \mathrm{ml}$ of $250 \mathrm{mM}$ $\mathrm{NaCl}$ solution. In control, the distilled water was used. The experiment was arranged in a randomized complete block design with three replicates. The Petri dishes were sealed with parafilm and cultured in an artificial climate chest at $27^{\circ} \mathrm{C}$ with $75 \%-80 \%$ relative humidity. After 12 days, the germination rate (GR) of each genotype was determined. Then, the relative salt-injury rate (RSR) at the germination stage was calculated via the following formulae [9], and salt tolerance was correspondingly divided into five grades (Table 2):

$$
\mathrm{RSR}=\frac{\mathrm{GR}_{\mathrm{ck}}-\mathrm{GR}_{\mathrm{st}}}{\mathrm{GR}_{\mathrm{ck}}} \times 100 \%,
$$

where RSR is the relative salt-injury rate at the germination stage and $G_{\mathrm{st}}$ and $\mathrm{GR}_{\mathrm{ck}}$ represent the value of $\mathrm{GR}$ for germplasm under salt-stressed and control conditions, respectively.

2.3. Identification of Salt Tolerance at the Seedling Stage. For each asparagus germplasm, the germinated seeds were sown in plastic pots $(15 \mathrm{~cm}$ diameter, one seedling/pot) with garden soil, vermiculite, and peat $(4: 3: 3, \mathrm{v} / \mathrm{v} / \mathrm{v})$ in an artificial weather room at an ambient temperature of $28^{\circ} \mathrm{C} /$ $19^{\circ} \mathrm{C}$ (day/night), the light intensity of $40000 \mathrm{lux}$, and a photoperiod of $10 \mathrm{~h}$ light $/ 4 \mathrm{~h}$ dark. Then, 35-day-old seedlings were subjected to salinity stress and control treatments with nine replicates in each treatment on each asparagus germplasm. For the salt treatment group, seedlings were irrigated with $300 \mathrm{ml}$ of $200 \mathrm{mM} \mathrm{NaCl}$ solution, while the controls were irrigated with distilled water. Plant injury was visually ranked at the termination of the 14-day stress treatment after the first salt treatment. Ranking of the standard and calculation of the salt-injury index (SI) followed the method of Zhen et al. [10], with some modification. The ranking criteria of salt-injury are presented in Table 3. The salt-injury index (SI) was calculated using the following equation:

$$
\begin{aligned}
\mathrm{SI}= & {\left[\sum \frac{\left(N_{0} \times 0+N_{1} \times 1+N_{2} \times 2+N_{3} \times 3+N_{4} \times 4\right)}{N \times 4}\right] } \\
& \times 100 \%,
\end{aligned}
$$

where $N$ is the number of total seedlings; $N_{O}$ is the number of level 0 seedlings; $N_{1}$ is the number of level 1 seedlings; $N_{2}$ is the number of level 2 seedlings; $N_{3}$ is the number of level 3 seedlings; and $N_{4}$ is the number of level 4 seedlings. According to the value of SI, salt tolerance at the seedling stage was divided into five grades. The grading standard is shown in Table 2.

\subsection{Identification of Salt Tolerance at the Adult Stage}

2.4.1. Experimental Treatment and Trait Measurement. The experiment at the adult stage was conducted in the artificial weather room of the Institute of Cash Crops, Hebei Academy of Agriculture and Forestry Sciences, China. On February 20, 2020, 30 70-day-old asparagus seedlings for each genotype were transplanted in pots containing $15 \mathrm{~kg}$ fertile soil (1.1\% organic matter, $347 \mathrm{mg} / \mathrm{kg}$ total $\mathrm{N}, 17.5 \mathrm{mg} /$ $\mathrm{kg}$ available $\mathrm{P}$, and $152 \mathrm{mg} / \mathrm{kg}$ available $\mathrm{K}$ ), with the tray at the bottom preventing water leakage. After seven days, each pot was watered with $2 \mathrm{~L} 200 \mathrm{mM} \mathrm{NaCl}$ solution every 24 hours for three days, or with an equal volume of distilled water for controls. After these, all pots with seedlings were 
TABLE 1: Name, origin, and the salt tolerance grades of the 95 asparagus accessions at each growth stage.

\begin{tabular}{|c|c|c|c|c|c|c|c|c|}
\hline \multirow{2}{*}{ Number } & \multirow{2}{*}{ Name } & \multirow{2}{*}{ Origin } & \multicolumn{2}{|c|}{ Germination stage } & \multicolumn{2}{|c|}{ Seedling stage } & \multicolumn{2}{|c|}{ Adult stage } \\
\hline & & & RSR (\%) & Grade & SI (\%) & Grade & MVFS & Grade \\
\hline 1 & Apllo & The United States & 23.43 & 2 & 41.5 & 3 & 0.76 & 1 \\
\hline 2 & UC115 & The United States & 18.34 & 1 & 57.6 & 3 & 0.65 & 2 \\
\hline 3 & UC157 & The United States & 11.24 & 1 & 53.5 & 3 & 0.52 & 3 \\
\hline 4 & UC800 & The United States & 83.44 & 5 & 66.5 & 4 & 0.36 & 3 \\
\hline 5 & NJ800 & The United States & 27.07 & 2 & 56.5 & 3 & 0.76 & 1 \\
\hline 6 & NJ857 & The United States & 13.03 & 1 & 26.5 & 2 & 0.60 & 3 \\
\hline 7 & NJ951 & The United States & 50.87 & 3 & 67.8 & 4 & 0.55 & 3 \\
\hline 8 & NJ956 & The United States & 81.16 & 5 & 51.8 & 3 & 0.30 & 4 \\
\hline 9 & NJ978 & The United States & 71.07 & 4 & 78.6 & 4 & 0.41 & 3 \\
\hline 10 & NJ1089 & The United States & 8.85 & 1 & 68.2 & 4 & 0.36 & 3 \\
\hline 11 & NJ1123 & The United States & 83.61 & 5 & 38.5 & 2 & 0.29 & 4 \\
\hline 12 & NJ1156 & The United States & 42.49 & 3 & 78.8 & 4 & 0.63 & 2 \\
\hline 13 & NJ1189 & The United States & 23.55 & 2 & 62.5 & 4 & 0.55 & 3 \\
\hline 14 & NJ1191 & The United States & 41.72 & 3 & 63.8 & 4 & 0.65 & 2 \\
\hline 15 & Grande & The United States & 22.46 & 2 & 71.8 & 4 & 0.59 & 3 \\
\hline 16 & Walker pioneer & The United States & 40.04 & 3 & 66.7 & 4 & 0.65 & 2 \\
\hline 17 & Walker deluxe & The United States & 63.50 & 4 & 39.2 & 2 & 0.48 & 3 \\
\hline 18 & Purple passion & The United States & 53.38 & 3 & 68.9 & 4 & 0.46 & 3 \\
\hline 19 & Trillon & The United States & 66.01 & 4 & 28.5 & 2 & 0.58 & 3 \\
\hline 20 & Patron & The United States & 37.79 & 2 & 60.1 & 4 & 0.48 & 3 \\
\hline 21 & Jersey night & The United States & 20.99 & 2 & 12.8 & 1 & 0.61 & 3 \\
\hline 22 & Jersey supreme & The United States & 51.61 & 3 & 70.8 & 4 & 0.44 & 3 \\
\hline 23 & Jersey giant & The United States & 37.51 & 2 & 72.5 & 4 & 0.45 & 3 \\
\hline 24 & Jersey knight & The United States & 42.50 & 3 & 61.2 & 4 & 0.37 & 3 \\
\hline 25 & Male crown & The United States & 28.69 & 2 & 42.7 & 3 & 0.52 & 3 \\
\hline 26 & Atlas & The United States & 13.30 & 1 & 68.7 & 4 & 0.68 & 2 \\
\hline 27 & Florida & The United States & 83.76 & 5 & 47.9 & 3 & 0.40 & 3 \\
\hline 28 & Early Califomia & The United States & 94.20 & 5 & 59.2 & 3 & 0.63 & 2 \\
\hline 29 & Imperial & The United States & 74.71 & 4 & 99.2 & 5 & 0.52 & 3 \\
\hline 30 & $\mathrm{~Wb}-210$ & The United States & 43.93 & 3 & 67.1 & 4 & 0.49 & 3 \\
\hline 31 & WB-215 & The United States & 52.65 & 3 & 77.6 & 4 & 0.49 & 3 \\
\hline 32 & Ariane & Germany & 58.33 & 3 & 69.2 & 4 & 0.20 & 5 \\
\hline 33 & Eposs & Germany & 35.66 & 2 & 50.4 & 3 & 0.19 & 5 \\
\hline 34 & European man & Germany & 30.32 & 2 & 62.5 & 4 & 0.39 & 3 \\
\hline 35 & Pacific purple & New Zealand & 34.65 & 2 & 77.3 & 4 & 0.50 & 3 \\
\hline 36 & Pacific challenger & New Zealand & 33.71 & 2 & 65.4 & 4 & 0.46 & 3 \\
\hline 37 & Taramec & New Zealand & 54.16 & 3 & 38.9 & 2 & 0.29 & 4 \\
\hline 38 & Pacific green & New Zealand & 14.66 & 1 & 43.9 & 3 & 0.52 & 3 \\
\hline 39 & JWC1 & New Zealand & 21.85 & 2 & 63.7 & 4 & 0.47 & 3 \\
\hline 40 & Pacific 2000 & New Zealand & 61.56 & 4 & 29.5 & 2 & 0.36 & 3 \\
\hline 41 & Vittorio & Italy & 53.98 & 3 & 81.6 & 5 & 0.28 & 4 \\
\hline 42 & Fo5030115 & Italy & 57.75 & 3 & 33.5 & 2 & 0.31 & 4 \\
\hline 43 & Fo5030215 & Italy & 31.56 & 2 & 16.7 & 1 & 0.60 & 3 \\
\hline 44 & Italo & Italy & 10.59 & 1 & 64.1 & 4 & 0.48 & 3 \\
\hline 45 & Enos & Italy & 64.48 & 4 & 74.8 & 4 & 0.51 & 3 \\
\hline 46 & Franklim & Holland & 48.36 & 3 & 87.5 & 5 & 0.65 & 2 \\
\hline 47 & Gynlim & Holland & 29.27 & 2 & 70.8 & 4 & 0.48 & 3 \\
\hline 48 & Boolim & Holland & 73.14 & 4 & 38.9 & 2 & 0.47 & 3 \\
\hline 49 & Gijnlim & Holland & 55.80 & 3 & 45.6 & 3 & 0.26 & 4 \\
\hline 50 & Limbras 10 & Holland & 37.25 & 2 & 67.2 & 4 & 0.52 & 3 \\
\hline 51 & Thielim & Holland & 67.93 & 4 & 82.9 & 5 & 0.41 & 3 \\
\hline 52 & Taramea & Holland & 34.92 & 2 & 61.4 & 4 & 0.41 & 3 \\
\hline 53 & James & Holland & 52.00 & 3 & 51.3 & 3 & 0.26 & 4 \\
\hline 54 & Diamonds & Holland & 53.45 & 3 & 97.2 & 5 & 0.26 & 4 \\
\hline 55 & Crown 300 & Holland & 41.83 & 3 & 73.6 & 4 & 0.55 & 3 \\
\hline 56 & Granno & Holland & 33.26 & 2 & 15.2 & 1 & 0.43 & 3 \\
\hline 57 & Welcom & Japan & 57.53 & 3 & 63.5 & 4 & 0.69 & 2 \\
\hline 58 & Accell & Japan & 67.22 & 4 & 33.8 & 2 & 0.38 & 3 \\
\hline 59 & Shower & Japan & 67.24 & 4 & 68.4 & 4 & 0.45 & 3 \\
\hline
\end{tabular}


TABLE 1: Continued.

\begin{tabular}{|c|c|c|c|c|c|c|c|c|}
\hline \multirow{2}{*}{ Number } & \multirow{2}{*}{ Name } & \multirow{2}{*}{ Origin } & \multicolumn{2}{|c|}{ Germination stage } & \multicolumn{2}{|c|}{ Seedling stage } & \multicolumn{2}{|c|}{ Adult stage } \\
\hline & & & RSR (\%) & Grade & SI (\%) & Grade & MVFS & Grade \\
\hline 60 & Mondeo & The United Kingdom & 62.97 & 4 & 18.9 & 1 & 0.39 & 3 \\
\hline 61 & Shuofeng & China & 56.01 & 3 & 72.5 & 4 & 0.44 & 3 \\
\hline 62 & Zhefeng-4112 & China & 63.93 & 4 & 58.8 & 3 & 0.20 & 5 \\
\hline 63 & Jiahui & China & 67.85 & 4 & 49.6 & 3 & 0.19 & 5 \\
\hline 64 & Prince & China & 83.40 & 5 & 42.6 & 3 & 0.34 & 3 \\
\hline 65 & Shengju-1 & China & 92.28 & 5 & 69.2 & 4 & 0.36 & 3 \\
\hline 66 & Sheng96-8 & China & 81.18 & 5 & 55.1 & 3 & 0.35 & 3 \\
\hline 67 & A11 & China & 64.14 & 4 & 67.2 & 4 & 0.43 & 3 \\
\hline 68 & Ji08-2 & China & 4.17 & 1 & 0 & 1 & 0.85 & 1 \\
\hline 69 & Jilulvwang & China & 47.23 & 3 & 66.5 & 4 & 0.41 & 3 \\
\hline 70 & Jinggang red & China & 73.20 & 4 & 46.6 & 3 & 0.65 & 2 \\
\hline 71 & Jinggang-701 & China & 61.45 & 4 & 26.6 & 2 & 0.53 & 3 \\
\hline 72 & Jing lv-1 & China & 45.47 & 3 & 52.4 & 3 & 0.32 & 3 \\
\hline 73 & Jing lv-2 & China & 47.18 & 3 & 62.8 & 4 & 0.33 & 3 \\
\hline 74 & Jing lv-3 & China & 50.42 & 3 & 91.2 & 5 & 0.26 & 4 \\
\hline 75 & Jing lv-1042 & China & 70.59 & 4 & 45.8 & 3 & 0.64 & 2 \\
\hline 76 & Jing lv-1040 & China & 76.35 & 4 & 86.4 & 5 & 0.45 & 3 \\
\hline 77 & Wei2014-1 & China & 73.23 & 4 & 58.9 & 3 & 0.36 & 3 \\
\hline 78 & Wei2014-2 & China & 67.95 & 4 & 95.8 & 5 & 0.38 & 3 \\
\hline 79 & TC & China & 44.21 & 3 & 32.6 & 2 & 0.80 & 1 \\
\hline 80 & Green spears & China & 71.86 & 4 & 98.5 & 5 & 0.44 & 3 \\
\hline 81 & Lu asp-1 & China & 33.65 & 2 & 43.8 & 3 & 0.54 & 3 \\
\hline 82 & Green foison & China & 48.09 & 3 & 55.3 & 3 & 0.63 & 2 \\
\hline 83 & Lu2000-3 & China & 55.59 & 3 & 64.6 & 4 & 0.45 & 3 \\
\hline 84 & Jx1502 & China & 4.39 & 1 & 21.8 & 2 & 0.82 & 1 \\
\hline 85 & Gold crown & China & 69.48 & 4 & 83.6 & 5 & 0.59 & 3 \\
\hline 86 & Jadeite Pearl & China & 56.34 & 3 & 43.8 & 3 & 0.30 & 4 \\
\hline 87 & New2030 & China & 44.16 & 3 & 65.1 & 4 & 0.47 & 3 \\
\hline 88 & Champion & China & 54.80 & 3 & 23.6 & 2 & 0.77 & 1 \\
\hline 89 & JK113 & China & 50.76 & 3 & 87.5 & 5 & 0.31 & 4 \\
\hline 90 & JK1125 & China & 14.60 & 1 & 57.6 & 3 & 0.32 & 3 \\
\hline 91 & BJ14001 & China & 35.79 & 2 & 48.6 & 3 & 0.36 & 3 \\
\hline 92 & BJ14003 & China & 68.03 & 4 & 52.8 & 3 & 0.43 & 3 \\
\hline 93 & BJ14004 & China & 70.18 & 4 & 70.9 & 4 & 0.37 & 3 \\
\hline 94 & BJ14006 & China & 61.02 & 4 & 68.5 & 4 & 0.46 & 3 \\
\hline 95 & C9-12 & China & 51.55 & 3 & 38.5 & 2 & 0.77 & 1 \\
\hline
\end{tabular}

$1,2,3,4$, and 5 in the last three columns represent the germplasm accessions of highly salt-tolerant, salt-tolerant, moderately salt-tolerant, salt-sensitive, and highly salt-sensitive, respectively. RSR: the relative salt-injury rate; SI: the salt-injury index; MFVS: the membership function value of salt tolerance.

TABLE 2: Grading standard of salt tolerance at the germination stage and seedling stage.

\begin{tabular}{lccc}
\hline Grade & Salt tolerance & RSR (\%) & SI (\%) \\
\hline 1 & Highly salt-tolerant & $0.0-20.0$ & $0.0-20.0$ \\
2 & Salt-tolerant & $20.1-40.0$ & $20.1-40.0$ \\
3 & Moderately salt-tolerant & $40.1-60.0$ & $40.1-60.0$ \\
4 & Salt-sensitive & $60.1-80.0$ & $60.1-80.0$ \\
5 & Highly salt-sensitive & $80.1-100.0$ & $80.1-100.0$ \\
\hline
\end{tabular}

${ }^{\mathrm{z}} \mathrm{RSR}$ : the relative salt-injury rate at the germination stage; SI: the salt-injury index at the seedling stage.

watered with $2 \mathrm{~L}$ distilled water every 10 days and cultured in an artificial weather room at the temperature of $28^{\circ} \mathrm{C} / 19^{\circ} \mathrm{C}$ (day/night), the light intensity of 50000 lux, and a photoperiod of $12 \mathrm{~h}$ light $/ 12 \mathrm{~h}$ dark.

On September 10, 2020, the whole plant was dug out and nine traits were determined, including plant height $(\mathrm{PH})$, the diameter of the stalk (DS), the diameter of the basal plate (DBP), the number of stalks (NS), the number of roots (NR), the fresh weight of aboveground part (FWA), the dry weight of aboveground part (DWA), the fresh weight of underground part (FWU), and the dry weight of underground part (DWU).

2.4.2. Data Analysis. Nine traits as indicators of salt tolerance were evaluated based on analysis of the genetic coefficient of variation, heritability, salt-tolerant coefficient, and membership function value of all the investigated traits with Microsoft Excel 2013 and SPSS 20.0 software [11]. ANOVA, Duncan's multiple comparison, and Pearson correlation analysis in our study were performed with SPSS software.

The genetic coefficient of variation $\left(\mathrm{CV}_{\mathrm{g}}\right)$ of each trait was calculated using the following equation: 
TABLE 3: The ranking criteria of seedlings after salt treatment.

\begin{tabular}{lc}
\hline Level & Ranking criteria \\
\hline 0 & Normal growth without symptoms of injury \\
1 & Approximately normal growth but with chlorosis and etiolation symptoms at the top of newborn spears \\
2 & Inhibited growth and with etiolated leaves (cladodes) in all newborn spears and less than $20 \%$ dried stalks \\
3 & Severely inhibited growth and with completely etiolated leaves aboveground and between $20 \%$ and $60 \%$ dried stalks \\
4 & Almost dead or certified death and with more than $60 \%$ dried stalks \\
\hline
\end{tabular}

$$
\mathrm{CV}_{g}=\frac{\sqrt{V_{g}}}{\bar{X}}=\sqrt{\frac{\left(G_{k}-S G_{j k}\right) / i j}{\bar{X}}} \times 100 \%,
$$

where $V_{g}$ is the genotypic variance; $\bar{X}$ is the average value of the trait under the two salt treatments; $G_{k}$ is the mean square of the genotype under the two salt treatments; $\mathrm{SG}_{\mathrm{jk}}$ is the mean square of the interaction between salt treatments and the genotype; $i$ is the number of replications; $j$ is the number of salt treatments; and $k$ is the number of genotypes.

The broad-sense heritability $\left(\mathrm{H}^{2}\right)$ of each trait was calculated using the following equation:

$$
H^{2}=\frac{V_{g}}{V_{p}}=\frac{V_{g}}{V_{g}+V_{s g}+V_{\varepsilon}}=\frac{\left(G_{k}-\mathrm{SG}_{\mathrm{jk}}\right) / i j}{\left(G_{k}-\mathrm{SG}_{\mathrm{jk}}\right) / i j+\left(\mathrm{SG}_{\mathrm{jk}}-\varepsilon\right) / i},
$$

where $V_{p}$ is the phenotypic variance; $V_{\mathrm{sg}}$ is the interactive variance between salt treatments and the genotype; $V_{\varepsilon}$ is the variance of error; and $\varepsilon$ is the mean square of the error.

The salt-tolerant coefficient (SC) was calculated using the following equation $[12,13]$ :

$$
\mathrm{SC}_{\mathrm{tg}}=\frac{X_{\mathrm{tgst}}}{X_{\mathrm{tgck}}}
$$

where $\mathrm{SC}_{\mathrm{tg}}$ is the salt-tolerant coefficient of trait $(t)$ for genotype $(g)$ and $X_{\text {tgst }}$ and $X_{\text {tgck }}$ are the values of the trait $(t)$ for the genotype $(g)$ evaluated in the salt treatment and control group, respectively.

Asparagus salt tolerance was evaluated by the membership function value (MFV) using the fuzzy comprehensive evaluation method [11]. The modified membership function value of salt tolerance (MFVS) was calculated using the following equation:

$$
\begin{aligned}
& \mathrm{U}_{\mathrm{tg}}=\frac{\mathrm{SC}_{\mathrm{tg}}-\mathrm{SC}_{\mathrm{tmin}}}{\mathrm{SC}_{\mathrm{tmax}}-\mathrm{SC}_{\mathrm{t} \min }} \\
& U_{g}=\frac{1}{n} \sum_{g=1}^{g} U_{\mathrm{tg}},
\end{aligned}
$$

where $U_{t g}$ is the membership function value for salt tolerance of trait $(t)$ for genotype $(g) ; \mathrm{SC}_{\mathrm{tmin}}$ and $\mathrm{SC}_{\text {tmax }}$ are the respective minimum and maximum values for the salt-tolerant coefficient of trait $(t)$; and $U_{g}$ is the average value of the membership function of nine traits for the genotype $(g)$ for salt tolerance.
Salt tolerance was divided into five grades according to the average value $(\bar{U})$ and standard deviation (SD) of MFVS. The grade standard for the salt tolerance of asparagus was established based on a study by Chen et al. [11]: if $U_{g} \geq \bar{U}+1.64 \mathrm{SD}$, highly salt-tolerant; $\bar{U}+1 \mathrm{SD} \leq U_{g}$ $<\bar{U}+1.64 \mathrm{SD}$, salt-tolerant; $\bar{U}-1 \mathrm{SD} \leq U_{g}<\bar{U}+1 \mathrm{SD}$, moderately salt-tolerant; $\bar{U}-1.64 \mathrm{SD} \leq U_{g}<\bar{U}-1 \mathrm{SD}$, salt-sensitive; and $U_{g}<\bar{U}-1.64 \mathrm{SD}$, highly salt-sensitive.

\section{Results}

3.1. Salt Tolerance Evaluation of Asparagus at the Germination Stage. The effects of salt stress on GR of 95 asparagus germplasm accessions were evaluated. The germination of seeds of the 95 asparagus germplasm accessions was generally normal under control conditions with an average GR of $94.51 \%$ and standard deviation of $4.15 \%$, whereas the mean value under the salt-stressed conditions (47.71\%) decreased by half. ANOVA further revealed a highly significant variation between the two salinity conditions for GR tested at $P<0.001$, which showed that salt stress significantly affected the seed germination of asparagus. Additionally, ANOVA revealed highly significant variations among genotypes for GR at $P<0.001$. To reflect the differences in salt tolerance among different germplasm accessions, the RSR value of GR was calculated, which had a relatively high coefficient of variation (0.43) among genotypes and followed a normal distribution. Thus, the germplasm accessions with different salt tolerance were effectively distinguished under our experimental conditions according to the grading standard in Table 2. As a result, 10 germplasm accessions were highly salt-tolerant, 20 germplasm accessions were salttolerant, 32 germplasm accessions were moderately salttolerant, 25 germplasm accessions were salt-sensitive, and eight germplasm accessions were highly salt-sensitive (Table 1 ). The 10 highly salt-tolerant germplasm accessions are Ji08-2, Jx1502, NJ1089, Italo, UC157, NJ857, Atlas, JK1125, Pacific green, and UC115.

3.2. Salt Tolerance Evaluation of Asparagus at the Seedling Stage. At the seedling stage, all germplasm accessions grew normally, with SI values of 0 under control conditions. However, the SI values of most germplasm accessions under salt-stressed conditions showed an obvious increasing trend with a coefficient of variation of 0.35 among different genotypes and followed a normal distribution. It showed the varying degrees of injury caused by salt stress. According to the grading standard (Table 2), five germplasm accessions were highly salt-tolerant, 14 germplasm accessions were salt- 
tolerant, 26 germplasm accessions were moderately salttolerant, 39 germplasm accessions were salt-sensitive, and 11 germplasm accessions were highly salt-sensitive (Table 1). The five highly salt-tolerant germplasm accessions are Ji08-2, Jersey night, Granno, Fo5030215, and Mondeo. The SI of Ji08-2 was 0; in other words, all the Ji08-2 seedlings grew normally without obvious symptoms of injury under salt stress, which is worthy of our particular attention for its application in subsequent research and production.

\subsection{Salt Tolerance Evaluation of Asparagus at the Adult Stage}

3.3.1. Response of Traits to Salt Stress. Phenotypic variation was confirmed by the average phenotypic value, SD, and SC of each investigated trait at the adult stage (Table 4). The mean values of all nine traits decreased under salt treatment. ANOVA revealed highly significant variations between two salinity conditions for all nine traits tested at $P<0.001$ (Table 5). Among the nine traits, FWA and DWA decreased by more than $60 \%$ under salt-stressed conditions compared with the control. Further variance analysis and Duncan's multiple comparison indicated that there was a significant difference $(P<0.05)$ between the SC of these two traits and other traits, indicating that these two traits were very sensitive to salt stress while the decreased ratio of other traits (DS, DBP, NS, FWU, DWU, NR, PH, FWA, and DWA) compared with the control was in the range from $42 \%$ to $51 \%$. Additionally, ANOVA revealed highly significant variations among the genotypes for all nine tested traits at $P<0.001$ (Table 5), and the interactions between genotype and salt treatment for all traits were also significant $(P<0.001)$.

3.3.2. Genetic Variation and Broad-Sense Heritability of the Investigated Traits. The $\mathrm{CV}_{g}$ values for the nine investigated traits ranged from $13.34 \%$ to $39.84 \%$ (Table 5). The $\mathrm{CV}_{g}$ values of DWA, FWA, and NS exceeded 30\%, i.e., $39.84 \%$, $38.94 \%$, and $30.44 \%$, respectively. For six other traits $(\mathrm{PH}$, DS, NR, DBP, DWU, and FWU), the $\mathrm{CV}_{g}$ values were in the range of $13.34 \%$ to $29.28 \%$. These results indicated that there were significant genotypic variations among the 95 accessions with respect to the investigated traits under both salinity conditions.

The $\mathrm{H}^{2}$ values of the nine investigated traits were analyzed. Their values reached medium to high levels, ranging from 0.36 to 0.82 , suggesting these traits are stable and suitable to be applied in the assessment systems. The heritability values of DS, NS, NR, DWU, and FWA were relatively high, i.e., $0.82,0.71,0.64,0.61$, and 0.60 , respectively. Among all the traits, $\mathrm{PH}$ had the lowest heritability of 0.36 . FWU, DWU, and DBP had moderate heritability with values of $0.56,0.44$, and 0.43 , respectively.

3.3.3. Identification of Salt Tolerance among Asparagus Germplasm Accessions. MFVS was used as a comprehensive index to evaluate the salt tolerance of the asparagus germplasm accessions. The estimated MFVS values of the 95
TABLE 4: The mean value and standard deviation (SD) of traits investigated under two salinity conditions and the salt-tolerant coefficient (SC) of each trait.

\begin{tabular}{|c|c|c|c|}
\hline Traits & $\begin{array}{c}\text { Mean } \pm \text { SD } \\
\quad \text { (salt) }\end{array}$ & $\begin{array}{c}\text { Mean } \pm \text { SD } \\
\text { (control) }\end{array}$ & $\begin{array}{l}\text { Mean } \pm \text { SD } \\
\quad(S C)\end{array}$ \\
\hline $\mathrm{DS}(\mathrm{mm})$ & $4.24 \pm 0.98$ & $7.32 \pm 1.24$ & $0.58 \pm 0.08 \mathrm{~A}$ \\
\hline $\begin{array}{l}\text { DBP } \\
(\mathrm{cm})\end{array}$ & $4.26 \pm 1.40$ & $7.78 \pm 1.33$ & $0.55 \pm 0.16 \mathrm{AB}$ \\
\hline NS & $12.13 \pm 5.13$ & $22.10 \pm 6.95$ & $0.55 \pm 0.13 \mathrm{AB}$ \\
\hline FWU (g) & $1052.54 \pm 348.12$ & $1954.78 \pm 414.59$ & $0.54 \pm 0.14 \mathrm{ABC}$ \\
\hline $\begin{array}{l}\text { DWU } \\
(\mathrm{g})\end{array}$ & $375.12 \pm 142.13$ & $740.10 \pm 190.87$ & $0.52 \pm 0.17 \mathrm{BC}$ \\
\hline NR & $125.62 \pm 49.38$ & $245.18 \pm 81.66$ & $0.52 \pm 0.13 \mathrm{BC}$ \\
\hline $\mathrm{PH}(\mathrm{cm})$ & $93.22 \pm 37.90$ & $187.41 \pm 21.85$ & $0.49 \pm 0.18 \mathrm{C}$ \\
\hline FWA (g) & $691.88 \pm 469.87$ & $1733.36 \pm 720.78$ & $0.39 \pm 0.17 \mathrm{D}$ \\
\hline $\begin{array}{l}\text { DWA } \\
(\mathrm{g})\end{array}$ & $112.60 \pm 82.54$ & $299.83 \pm 124.21$ & $0.36 \pm 0.18 \mathrm{D}$ \\
\hline
\end{tabular}

DS: the diameter of the stalk; DBP: the diameter of the basal plate; NS: the number of stalks; FWU: the fresh weight underground; DWU: the dry weight underground; NR: the number of roots; PH: plant height; FWA: the fresh weight of the aboveground part; DWA: the dry weight of the aboveground part. Values with different capital letters in the last column indicate a significant difference $(P<0.05)$.

asparagus accessions based on the traits under the two salinity conditions are presented in Table 1, and their distribution was normal. The minimum and maximum values of MFVS were 0.19 (Eposs) and 0.85 (Ji08-2), respectively. Among the 95 asparagus accessions, seven accessions (Apllo, Ji08-2, Jx1502, TC, Champion, C9-12, and NJ800) were highly salt-tolerant; 11 accessions including Welcom, Atlas, Franklim, and NJ1191 were salt-tolerant. Results indicate that these 18 accessions with MVFS values ranging from 0.62 to 0.84 are optimal in saline soils. By contrast, 4 accessions and 11 accessions were classified as highly salt-sensitive and salt-sensitive, with MFVS values ranging from 0.19 to 0.32 , which demonstrates that these asparagus accessions are not suitable for planting in saline soils. The remaining $62 \mathrm{ac}-$ cessions were regarded as moderately salt-tolerant, with MFVS values ranging from 0.33 to 0.61 .

3.4. Comparison of Salt Tolerance among Germination, Seedling, and Adult Stages. After the evaluation of the salt tolerance of 95 asparagus accessions at each growth stage, we obtained some tolerant germplasm accessions, including highly salt-tolerant and salt-tolerant germplasm accessions that had high potential for further application in saline soils and breeding. There were a total of 30 tolerant germplasm accessions at the germination stage, 19 at the seedling stage, and 18 at the adult stage. In order to further explore the relationships among salt tolerance identified from the three growth stages, Venn diagrams were constructed to detect both unique and overlapping sets of the tolerant germplasm accessions in different stages (Figure 1). Among them, there were six germplasm accessions common to the germination stage and seedling stage, five common to the seedling stage and adult stage, and six common to the adult stage and germination stage, while only two germplasm accessions (Ji08-2 and Jx1502) were simultaneously detected in all three 


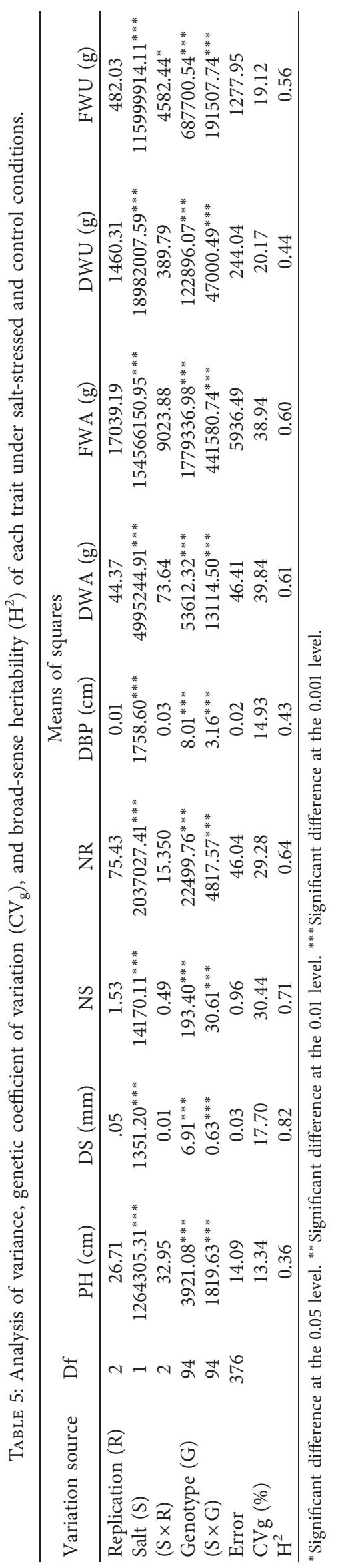




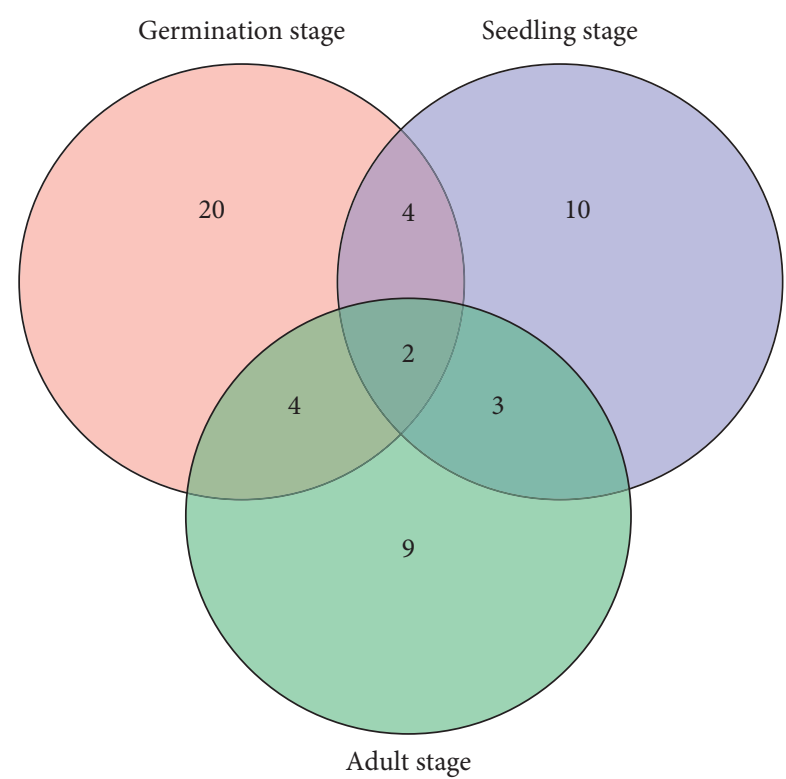

Figure 1: Venn diagrams showing specific and common tolerant germplasm accessions in the three growth stages.

growth stages. In general, most of the tolerant germplasm accessions were specific to one growth stage. Additionally, the correlations of the salt tolerance grades of 95 asparagus accessions between any two growth stages were analyzed and none showed a significant correlation with the $P$ values of $0.346,0.081$, and 0.141 , respectively. This result indicated that there may be no direct connection between the salt tolerance identified at different growth stages, and the identified results at each stage may show their own biological significance.

\section{Discussion}

It is well known that salt stress severely impacts crop production worldwide by reducing growth and yield $[14,15]$. Specifically, the growth parameters of different germplasms show significantly different responses to salt stress, such as the germplasms of cucumber, tomato, and chilli [6-8]. In asparagus, we also found that 95 germplasm accessions exhibited different salt tolerance with a large variation. Overall, the growth of most germplasm accessions was obviously inhibited by salt stress. For instance, the mean value of the seed germination rate decreased by half under the salt-stressed condition compared to the control; the mean SI at the seedling stage reached 57.68\%; and FWA and DWA at the adult stage decreased by more than $60 \%$. Therefore, it is crucial for future research and production to screen salt-tolerant asparagus germplasm accessions through appropriate means.

Differences in salt tolerance occur not only among different germplasms but also at different developmental stages of the same germplasm $[16,17]$, which may be related to different salt tolerance mechanisms. A large number of studies have shown that germination and seedling stages are the preferred periods when evaluating the salt tolerance of crops due to their sensitivity to salt and important roles in crop stand and eventual crop yield [18-21]. Another critical stage closer to actual production, the adult stage, has often been overlooked. Several studies have proved the predictive role of some adult asparagus characteristics on future yield [22], which simultaneously resolves the problem of great workload inherent in continuously measuring yield throughout the entire harvest season. Thus, identifying salttolerant adult plants will be more reliable when combined with the identification at the germination and seedling stage. In our study, the identified results of asparagus salt tolerance at the three above-mentioned growth stages were different and showed no significant correlation. Therefore, the identification of salt tolerance based on only one growth stage may be one-sided, and it is necessary to identify all the main growth stages in order to adequately assess the salt tolerance of asparagus.

Salt stress usually affects plant morphological development, which provides some visual and measurable appearances for the identification of salt tolerance. The germination stage of asparagus plants is characterized by the germination of seeds. At the germination stage, GR is an important indicator, and its RSR is a reliable indicator to distinguish germplasm accessions with different salt tolerances [23]. Plants at the seedling stage are vulnerable; saltsensitive and highly salt-sensitive germplasm accessions made up more than half of our germplasm accessions; and the symptoms of injury caused by salt stress were obvious, such as leaf chlorosis, growth inhibition, and even death. In this period, SI is suggested as an index for salt tolerance identification of perennial plants, based on the classification of the salt-injury level and the number of plants with a corresponding level [10], and can reflect the extent and intensity of salt injury to plants. Additionally, multiple indicators including the ground and underground parts of adult asparagus are correlated with future yield potential [22]. These traits in our asparagus germplasm accessions had adequate genetic variations and heritabilities, which are necessary guides for the breeding value and the trait utility within the selection process. In the case of multitrait evaluation, a comprehensive evaluation method, MFVS that combines the SC values of morphological traits, is often used $[11,18,23]$. In our study, the salt tolerance of 95 asparagus germplasm accessions was effectively distinguished according to the above methods, and their corresponding indicators (RSR, SI, and MFVS) for tolerance identification followed a normal distribution, indicating the rationality of our results. We obtained two germplasm accessions (Ji08-2 and Jx1502) that were simultaneously identified to be tolerant in all three growth stages and some other tolerant germplasm accessions tolerant at only one or two stages, which have a significant value for salt tolerance improvement in asparagus.

\section{Conclusion}

Ninety-five asparagus germplasm accessions were evaluated for their morphological traits under both salt and control conditions to screen the germplasm accessions for salt resistance at different growth stages. This work made it clear 
that a difference in the salt tolerance of asparagus occurred not only among different germplasms but also at different growth stages of the same germplasm. There were 30, 19, and 18 germplasm accessions that were identified to be tolerant (including highly salt-tolerant and salt-tolerant germplasm accessions) at the germination stage, seedling stage, and adult stage, respectively. Among them, only two germplasm accessions (Ji08-2 and Jx1502) were simultaneously identified to be tolerant at all three growth stages and have great potential for further use in saline soils and germplasm improvement. Other germplasm accessions were tolerant only at one or two stages, indicating that these germplasm accessions could be used to improve germplasm through a careful choice of crossing parents with complementary salt tolerance at certain stages.

\section{Data Availability}

All data generated or analyzed during this study are included in this article.

\section{Conflicts of Interest}

The authors declare that they have no conflicts of interest.

\section{Authors' Contributions}

Huimin Gao and Xuhong Zhang contributed equally to this work.

\section{Acknowledgments}

This work was supported by the Key R\&D Project of Hebei Province (19226334D), Scientific and Technological Innovation Projects of Hebei Province (20193-01-01), Applied Basic Research Projects of Yunnan Province (2018FG001028), National Key R\&D Program of China (2019YFD1002000), and "Giant Project" of Hebei Province (2018-3).

\section{References}

[1] Y. Zhang, Q. Yao, Y. Shi et al., "Elevated $\mathrm{CO}_{2}$ improves antioxidant capacity, ion homeostasis, and polyamine metabolism in tomato seedlings under $\mathrm{Ca}\left(\mathrm{NO}_{3}\right)_{2}$-induced salt stress," Scientia Horticulturae, vol. 273, Article ID 109644, 2020.

[2] C. Dawid and T. Hofmann, "Identification of sensory-active phytochemicals in Asparagus (Asparagus officinalisL.)," Journal of Agricultural and Food Chemistry, vol. 60, no. 48, pp. 11877-11888, 2012.

[3] Y. P. Cao, P. Dai, and S. Y. Dai, "Effects of salt stress on the growth of Asparagus officinalis L. seedlings and on $\mathrm{Na}^{+}, \mathrm{K}^{+}$ and $\mathrm{Ca}^{2+}$ distribution in them," Journal of Southwest University (Natural Science Edition), vol. 36, no. 10, pp. 31-36, 2014, in Chinese.

[4] X. Zhang, C. Han, and Y. Cao, "Transcriptomic and physiological analyses reveal the dynamic response to salinity stress of the garden asparagus (Asparagus officinalis L.)," Plant Molecular Biology Reporter, vol. 38, no. 4, pp. 613-627, 2020.

[5] Y. X. Zhang, L. J. Zhang, Y. S. Wang, W. W. Tan, and F. X. Niu, "Comparative analysis of effect of salt-alkaline stress on asparagus," Journal Anhui Agriculture Science, vol. 34, no. 18 , pp. 4687-4679, 2006, in Chinese.

[6] A. Marium, A. Kausar, S. Muhammad et al., "Assessment of cucumber genotypes for salt tolerance based on germination and physiological indices," Dose-Response, vol. 17, no. 4, pp. 1-8, 2019.

[7] J. Sivakumar, P. J. E. Prashanth, N. Rajesh, S. M. Reddy, and O. B. Pinjari, "Principal component analysis approach for comprehensive screening of salt stress-tolerant tomato germplasm at the seedling stage," Journal of Biosciences, vol. 45 , no. 1 , p. $141,2020$.

[8] K. Loganayaki, S. Tamizhmathi, D. Brinda, S. Gayathri, M. C. Mary, and V. Mohanlal, "In vitro evaluation of tomato (Lycopersicon esculentum Mill.), chilli (Capsicum annum L.), cucumber (Cucumis sativus L.) and Bhendi (Abelmoschus esculentus L.) for salinity stress," International Journal of Chemical Studies, vol. 8, no. 2, pp. 2364-2367, 2020.

[9] Q. Jiang, Z. Hu, H. Zhang et al., "Evaluation for salt tolerance in soybean cultivars ( Glycine max L. Merrill)," Journal of Plant Genetic Resources, vol. 13, no. 5, pp. 726-732, 2012, in Chinese.

[10] A. Zhen, Z. Bie, Y. Huang, Z. Liu, and Q. Li, "Effects of scion and rootstock genotypes on the anti-oxidant defense systems of grafted cucumber seedlings under $\mathrm{NaCl}$ stress," Soil Science and Plant Nutrition, vol. 56, no. 2, pp. 263-271, 2010.

[11] X. Chen, D. Min, T. A. Yasir, and Y.-G. Hu, "Evaluation of 14 morphological, yield-related and physiological traits as indicators of drought tolerance in Chinese winter bread wheat revealed by analysis of the membership function value of drought tolerance (MFVD)," Field Crops Research, vol. 137, pp. 195-201, 2012.

[12] A. Blum and W. R. Jordan, "Breeding crop varieties for stress environments," Critical Reviews in Plant Sciences, vol. 2, no. 3, pp. 199-238, 1985.

[13] F. Szira, A. F. Bálint, A. Börner, and G. Galiba, "Evaluation of drought-related traits and screening methods at different developmental stages in spring barley," Journal of Agronomy and Crop Science, vol. 194, no. 5, pp. 334-342, 2008.

[14] V. Chinnusamy, A. Jagendorf, and J.-K. Zhu, "Understanding and improving salt tolerance in plants," Crop Science, vol. 45, no. 2, pp. 437-448, 2005.

[15] T. J. Flowers, "Improving crop salt tolerance," Journal of Experimental Botany, vol. 55, no. 396, pp. 307-319, 2004.

[16] S. E. El-Hendawy, Y. Hu, G. M. Yakout, A. M. Awad, S. E. Hafiz, and U. Schmidhalter, "Evaluating salt tolerance of wheat genotypes using multiple parameters," European Journal of Agronomy, vol. 22, no. 3, pp. 243-253, 2005.

[17] L. Zeng, M. C. Shannon, and C. M. Grieve, "Evaluation of salt tolerance in rice genotypes by multiple agronomic parameters," Euphytica, vol. 127, no. 2, pp. 235-245, 2002.

[18] T. Ding, Z. Yang, X. Wei, F. Yuan, S. Yin, and B. Wang, "Evaluation of salt-tolerant germplasm and screening of the salt-tolerance traits of sweet sorghum in the germination stage," Functional Plant Biology, vol. 45, no. 10, pp. 1073-1081, 2018.

[19] A. Shekoofa, E. Bijanzadeh, Y. Emam, and M. Pessarakli, "Effect of salt stress on respiration of various wheat lines/ cultivars at early growth stages," Journal of Plant Nutrition, vol. 36, no. 2, pp. 243-250, 2013.

[20] L. Dong, W. Ravelombola, Y. Weng et al., "Seedling salt tolerance for above ground-related traits in cowpea (Vigna unguiculata (L.) Walp)," Euphytica, vol. 215, no. 53, pp. 1-22, 2019.

[21] F. Ledesma, C. Lopez, D. Ortiz et al., "A simple greenhouse method for screening salt tolerance in soybean," Crop Science, vol. 56, no. 2, pp. 585-594, 2016. 
[22] M. Knaflewski, W. Chen, W. Krzesinski, and A. Zaworska, "Characteristics of immature asparagus plants as possible indicators of their future yield," Acta Horticulturae, vol. 936, no. 936, pp. 365-372, 2012.

[23] H. Wu, J. R. Guo, C. F. Wang et al., "An effective screening method and a reliable screening trait for salt tolerance of Brassica napus at the germination stage," Front Plant Science, vol. 10, p. 530, 2019. 